\title{
Research on the Development Process and Trend of Unmanned Aerial Vehicle
}

\author{
Hongzhuan Cai ${ }^{1,}$, Qingkai Geng ${ }^{2, b}$ \\ ${ }^{1}$ Xijing University, No.1, Xijing Road, Chang'an, Xi'an, Shaanxi,710123 China \\ ${ }^{2}$ Xijing University, No.1, Xijing Road, Chang'an, Xi'an, Shaanxi,710123 China \\ achz191@126.com, b1056574145@qq.com
}

Keywords: Unmanned Aerial Vehicleoccer(UAV); Development; Trend

\begin{abstract}
UAV technology plays an increasingly important role in modern warfare. This paper introduces the development of UAV technology and equipment, improving the situation, pointing out the advantages and importance of the development of UAV technology in modern warfare, focusing on the performance of several UAV technology and its characteristics Finally, discusses the development trends and analysis of UAV technology.
\end{abstract}

\section{Introduction}

UAV(Unmanned aerial vehicle) is a kind of unmanned aircraft controled by radio remote control equipment or its program control device[1,2]. Its flight is either controlled autonomously by computers in the vehicle, or under the remote control of anavigator, or pilot (in military UAVs called a Combat Systems Officer on UCAVs) on the ground or in another vehicle.

There are a wide variety of drone shapes, sizes, configurations, and characteristics. Historically, UAVs were simple remotely piloted aircraft, but autonomous control is increasingly being employed.

Their largest use is within military applications. UAVs are also used in a small but growing number of civil applications, such as firefighting or nonmilitary security work, such as surveillance of pipelines. UAVs are often preferred for missions that are too "dull, dirty, or dangerous" for manned aircraft.

\section{Development Process}

The earliest attempt at a powered unmanned aerial vehicle was A. M. Low's "Aerial Target" of 1916. Nikola Tesla described a fleet of unmanned aerial combat vehicles in 1915. A number of remote-controlled airplane advances followed, including the Hewitt-Sperry Automatic Airplane, during and after World War I, including the first scale RPV (Remote Piloted Vehicle), developed by the film star and model airplane enthusiast Reginald Denny in 1935. More were made in the technology rush during World War II; these were used both to train antiaircraft gunners and to fly attack missions. Jet engines were applied after World War II, in such types as the Teledyne Ryan Firebee I of 1951, while companies like Beechcraft also got in the game with their Model 1001 for the United States Navy in 1955. Nevertheless, they were little more than remote-controlled airplanes until the Vietnam Era.

The birth of U.S. UAVs (called RPVs at the time) began in 1959 when United States Air Force (USAF) officers, concerned about losing pilots over hostile territory, began planning for the use of unmanned flights. This plan became intensified whenFrancis Gary Powers and his "secret" U-2 were shot down over the Soviet Union in 1960. Within days, the highly classified UAV program was launched under the code name of "Red Wagon." The August 2 and August 4, 1964, clash in the Tonkin Gulf between naval units of the U.S. and North Vietnamese Navy initiated America's highly classified UAVs into their first combat missions of the Vietnam War. When the "Red Chinese" showed photographs of downed U.S. UAVs via Wide World Photos, the official U.S. response was, "no comment." 
Only on February 26, 1973, during testimony before the United States House Committee on Appropriations, did the U.S. military officially confirm that they had been utilizing UAVs in Southeast Asia (Vietnam). While over 5,000 U.S. airmen had been killed and over 1,000 more were either missing in action (MIA), or captured (prisoners of war/POW); the USAF 100th Strategic Reconnaissance Wing had flown approximately 3,435 UAV missions during the war, at a cost of about 554 UAVs lost to all causes. In the words of USAF General George S. Brown, Commander, Air Force Systems Command in 1972, "The only reason we need (UAVs) is that we don't want to needlessly expend the man in the cockpit." Later that same year, General John C. Meyer, Commander in Chief, Strategic Air Command, stated, "we let the drone do the high-risk flying ... the loss rate is high, but we are willing to risk more of them ... they save lives!"

During the 1973 Yom Kippur War, Syrian missile batteries in Lebanon caused heavy damage to Israeli fighter jets. As a result, Israel developed the first modern UAV. Israel pioneered the use of UAVs for real-time surveillance, electronic warfare and decoys. The images and radar decoying provided by these UAVs helped Israel to completely neutralize the Syrian air defenses at the start of the 1982 Lebanon War, resulting in no pilots downed.

With the maturing and miniaturization of applicable technologies as seen in the 1980s and 1990s, interest in UAVs grew within the higher echelons of the U.S. military. In the 90s the U.S. Department of Defense began to buy UAVs from Israel. The Navy bought the Pioneer UAV, which is still in use. Many of these Israeli and newly developed U.S. UAVs were used in the 1991 Gulf War[3,4,5].

UAVs were seen to offer the possibility of cheaper, more capable fighting machines that could be used without risk to aircrews. Initial generations were primarily surveillance aircraft, but some were armed (such as the General Atomics MQ-1 Predator, which utilized AGM-114 Hellfire air-to-ground missiles). An armed UAV is known as an unmanned combat air vehicle (UCAV).

\section{Development Trend}

With the growing of real needs, the performance and functionality of UAV is continuously growing[6]. First of all, an important development direction is from low short voyage to high-altitude long-endurance. In the second place, the crucial development direction is stealth UAV. To deal with the increasing of ground air defense firepower, many advanced stealth technology and equipment has been applied to the development of UAV, such as composite material, the radar absorbing material, low noise engine. Thirdly, the significant development direction is from the real-time tactical reconnaissance direction to airborne early warning. Last but not the least is that an momentous development direction is air combat. Attack UAV is an vital development direction.

Ability of the UAV intelligence gathering and battlefield surveillance depends on the development of sensor technology. Strong commonality of UAV sensor is a long-term goal for unmanned aerial vehicle development. As the demand of the unmanned aerial vehicle been on the rise, the airborne sensor market has gained great development.This aspect of the key techniques include the following aspects. Compared with other system, multispectral/hyperspectral like (10 100 multispectral spectrum band, more than 100 hyperspectral spectrum), combined the characteristics of the panchromatic sensor and can obtain fine information from the target image. It also improve the clutter suppression, detection and target range of high reliability, etc. Synthetic aperture radar is likely to become the main future UAV sensor. It can pinpoint ground targets, through enhanced software processing algorithms. Its resolution will be able to reach more than $30 \mathrm{~cm}$. Synthetic aperture radar, based on active phased array technology and conformal antenna, has a good image and moving target indicator capability and can efficiently use space payloads. It become hot research focus. As an auxiliary sensor, it can find those targets who used the bunker or stealth technology.

In response to the allegations, communications integration battlefield management, UAV carried complex tasks and loads must collaborates with other manned aircraft, weapons systems and ground 
stations. A huge amount of information transmission, high data rate for real-time data link bandwidth, interception and anti-jamming capability, safety and reliability are all important.

As big combat radius, high altitude, usually flying over the horizon, the independent ability of UAV is very important. Especially when it losts contact with ground control station, the UAV must rely on the independent ability to complete the task or safe return.

According to different purposes, the development of the fuselage size of UAV is to two extreme aspects. On the one hand the development strategy of UAV is a larger overall size, and could replace the high-altitude airborne surveillance and communication platform. On the other hand the development tactical of UAV pursues a small and miniature size in order to improve mobility, survival ability and cost-effectiveness ratio.

\section{Summary}

Along with the rapid development of computer, communication, information fusion and artificial intelligence technology, the technology restrained the development of UAV problem will be solved one by one. The UAV is accelerating, as an indispensable weapon in integrated battlefield[7,8]. UAV -- the future three-dimensional battlefield generalists and fighting capacity of multiplier, will unveil a new chapter dominated by the long-distance intelligent attacking weapons and informationization of non-contact war.

\section{References}

[1] Li Chen, in: Military UAV technology development status and future trends, edtied by Aeronautical Science and Technology Magazine Publishing (2013).

[2] Wenzheng Li, in: UAV Development Discussion, edtied by Aeronautical Science and Technology Magazine Publishing (2012).

[3] Li Liu, Cenrui Ma, Dong Yuan, Zhanhui Chen, in: Research on the Development and Operational Use of UAV, edtied by Aerodynamic Missile Journal Magazine Publishing (2011).

[4] Ming Liu, Yi Sun, in: Analysis of the Development of Foreign Military UAV technology, edtied by Ship Electronic Engineering Magazine Publishing (2010).

[5] Yunhui Zhen, Ping Lu, in: UAV-related Technology and Development Trends, edtied by Ordnance Industry Automation Magazine Publishing (2009).

[6] Qiusheng Cao, Huijun Zhang, in: Explore UAV Development Characteristics and Technical Difficulties, edtied by Journal of China Academy of Electronics and Information Technology Publishing (2008).

[7] Shuyuan Wang, in: Foreign Military UAV Development Status and Trends, edtied by Silicon Valley Magazine Publishing (2014).

[8] Yumin Chang, in: UAV technology research status and development trend, edtied by Electronic Technology and Software Engineering Magazine Publishing (2014).

[9] Chengyuan Sun, in: The Development of Network Centric Warfare and UAV, edtied by Ship Electronic Engineering Magazine Publishing (2008).

[10] Xikang Cui, in: Burgeoning Foreign Military UAV System Development Plan, edtied by Aviation Weapon Magazine Publishing (2007). 